\title{
Effectiveness of a combined silver nanoparticles/fluoride varnish in dental remineralization in children: in vivo study
}

\author{
C. Butrón-Téllez Girón*, J. Mariel-Cárdenas \\ Facultad de Estomatología, Universidad Autónoma San Luis Potosí \\ San Luis Potosí, SLP, México \\ M. Pierdant-Pérez, J.F. Hernández-Sierra \\ Departamento de Epidemiología Clínica y Departamento de Salud Pública, Facultad de Medicina, \\ Universidad Autónoma de San Luis Potosí \\ San Luis Potosí, SLP, México \\ J.E. Morales-Sánchez, F. Ruiz ${ }^{\#}$ \\ Facultad de Ciencias, Universidad Autónoma de San Luis Potosí \\ San Luis Potosí, SLP, México \\ (Received: November 23rd, 2016; Accepted: May 9th, 2017)
}

\begin{abstract}
Dental caries is an infectious disease that can occur in children, sometimes as soon as the teeth eruption starts. Nanotechnology provides effective strategies in prevention and treatment of dental caries. The purpose of this study was to determine the effectiveness of the addition of silver nanoparticles to a fluoride varnish for the remineralization of primary teeth with white spot lesions. A trial was carried out in children with dental demineralization (white spot lesions) on both maxillary dental teeth. One of the teeth received three applications of a fluoride varnish with silver nanoparticles, and the other one, three applications of the same varnish without the silver nanoparticles. We measured the mineral content of the teeth with a laser cavity detection device (DIAGNOdent ${ }^{\circledR}$ ) before the first application of the varnishes, and 3 months after the last application. The results show significant differences between teeth treated with silver nanoparticles. Teeth have been treated with fluoride varnish added with silver nanoparticles seemed to enhance dental structure than teeth treated with conventional varnish, and this effect was also found between basal and final measurements in this group. The fluoride varnish added with silver nanoparticles seems to be more effective in the dental remineralization. This strategy may be used as a prophylactic measure to avoid development of caries.
\end{abstract}

\section{Introduction}

Many strategies have been developed for maintenance of the integrity of the enamel structure; the application of fluoride agents in various forms is a proven approach that strengthens the enamel structure [1]. Fluorinated varnishes have been used as preventive methods for caries development both in the general population, and in patients with special needs since they possess the ability to adhere to dental surfaces for relatively long time, and they do not require special application techniques [2-4]. These varnishes are also used in the treatment of white spot lesions (WSLs), which indicates dental demineralization; it has been supported that the early diagnosis or detection of WSLs and the use of non-invasive therapies such as fluoride are important strategies for controlling the development of dental caries [5]. Silver has been studied in several areas with the advent of nanotechnology, they have been synthesized [6,7]. Silver nanoparticles (AgNPs) have previously been used in dental applications, such as in dental restoration, endodontic cements for retro-filling, dental implants, and caries-inhibiting solutions [7-9], since several studies have demonstrated that they pursue a bactericidal effect, particularly against Streptococcus mutans, without pigmentation of the dental structure and no evidence of cytotoxicity [10-13]. AgNPs incorporation aims to avoid or at least to decrease the microbial colonization over dental materials increasing oral health levels [14]. The combination of these strategies may confer a better treatment of the WSLs; therefore, the purpose of this research was to determine the effectiveness of the addition of AgNPs to a fluoride varnish for the remineralization of white spot lesions, and to know if the fluoride varnish added with silver nanoparticles can be used to improve oral health quality and avoid the development of caries.

\section{Experimental details}

Synthesis and characterization of silver nanoparticles

Silver nanoparticles were prepared, as previously reported by Morales et al. [15], in an aqueous solution by reducing $\mathrm{Ag}+$ ions with albumin solution. The detailed synthetic procedure of silver nanoparticles is as follows: An albumin solution was prepared by dissolving 0.1 grams of albumin in $30 \mathrm{ml}$ of deionizer water. Another $\mathrm{Ag}+$ ion solution was prepared by dissolving 0.05 grams of $\mathrm{AgNO} 3$ in $10 \mathrm{ml}$ of deionizer water. The particles were prepared by mixing the silver ion solution with the albumin solution in a magnetic stirrer and after 5 minutes, $29.9 \%$ ammonium hydroxide was added in drop form, producing an adjustment of $\mathrm{pH}=11$. Albumin and $\mathrm{AgNO} 3$ were purchased from Sigma-Aldrich; ammonium hydroxide (29.9\%, Fermont) was used without any further purification. Mili-Q water $(18.2 \Omega$ ) was used throughout the experiment. In order to corroborate the silver nanoparticles presence, UV-vis absorption spectra were obtained with an Oceanoptics S2000-UV-Vis system. 
Transmission Electron Microscopy (TEM) images at $100 \mathrm{kV}$ were carried out using a JEOL-1230.

\section{Preparation of dental fluoride varnish containing silver nanoparticles}

For this preparation, the colloidal solution of AgNPs was filtered and afterward washed a minimum of 3 times with ethylic alcohol to remove residual ionic silver and other byproducts. After that, nanoparticles were dried to obtain a powder. A mixture of silver nanoparticles (powder) and fluoride varnish (Fluor Protector Varnish ${ }^{\circledR}$, Vivadent, Schaan, Liechtenstein) was prepared at $0.1 \%$ wt. In order to assure the homogenous incorporation of the AgNPs, the mixture was sonicated for $10 \mathrm{~min}$ using an ultrasonic sonicator probe (Q500, Qsonica, LLC). Silver concentration was selected 1000 times more concentrated than the MIC value obtained for these bacteria in previous studies [16].

\section{Patients and sample collection}

The study was realized in 22 children aged from 1 to 6 years. The criteria of inclusion were teeth with demineralization sites; clinically detected as opaque and porous white spot lesions on the vestibular surface of anterior and superior primary teeth. DIAGNOdent ${ }^{\circledR}$ laser cavity detection pen (KaVo, Biberach, Germany) was used to measure the teeth demineralization. Teeth were assigned one tooth of each hemi arc to the experimental treatment, which was the fluoride varnish added with $0.1 \% \mathrm{AgNPs}$; and the other one to the control treatment, which was the commercial fluoride varnish, thus the teeth were our experimental units.

These varnishes were applied in each teeth vestibular surface with a brush after they had been cleaned, dried with gases and isolated with cotton balls. Each tooth was subjected to these treatments once a week for a 3 weeks period, and the children received standard oral health care, they were followed up for 3 months afterward and measured by DIAGNOdent ${ }^{\circledR}$ to evaluate if there was a difference between groups. There were any drop-outs from the study.

Evaluations at all visits were carried out by the same Pediatric Odontologist; who was blinded to the treatment assignment. Reproducibility of the measurements conducted with the DIAGNOdent ${ }^{\circledR}$ in children by two observers (inter/intra observer agreement) was evaluated, performing

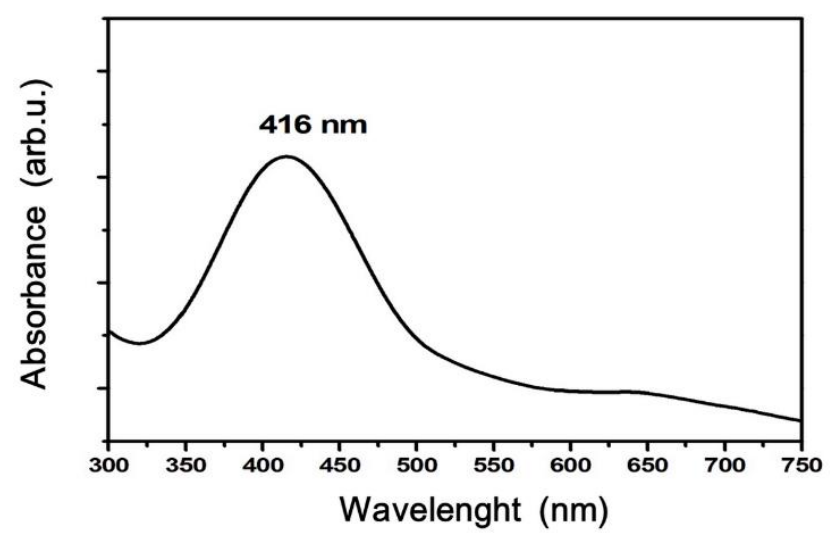

Figure 1. UV-Vis spectra of the silver nanoparticles synthesized. the Shrout and Fleiss intraclass 3,1 correlation coefficient. The reproducibility of the measurements; the inter observer and intra observer agreement were 100 and $99 \%$, respectively.

\section{Statistical analysis}

Statistical analysis was carried out in the statistical package R-3.0.1 (R Development Core Team 2013) at a $95 \%$ Confidence Interval (95\% CI). Results are expressed as mean \pm SD. The assumption of normal distribution of the data was confirmed through Shapiro-Wilk tests, and a parametric analysis was performed with a paired Student's t-test between basal and final measurements. A value of $\mathrm{p}<0.05$ was considered to be statistically significant.

\section{Results and discussion}

The absorption spectra of the AgNPs are presented in Figure 1; the spectrum shows the characteristic Surface Plasmon (SP) of silver nanoparticles at $416 \mathrm{~nm}$. Figure 2 shows TEM images, it is possible to observe that AgNPs are monodispersed having pseudospherical shapes and an average size of $46 \mathrm{~nm}$.

DIAGNOdent $\AA$ basal measurements were similar between the AgNPs varnish treated teeth $(5.68 \pm 1.0$ fluorescence intensity) and the commercial varnish treated teeth (5.50 \pm 0.8 fluorescence intensity) $(p=0.53)$. At the end of the 3-month follow-up, final measurements were taken again. Teeth treated with the AgNPs varnish had less mean fluorescence intensity than the group treated with commercial varnish $(3.68 \pm 1.2$ vs. $5.09 \pm 1.0, \mathrm{p}<0.001)$,
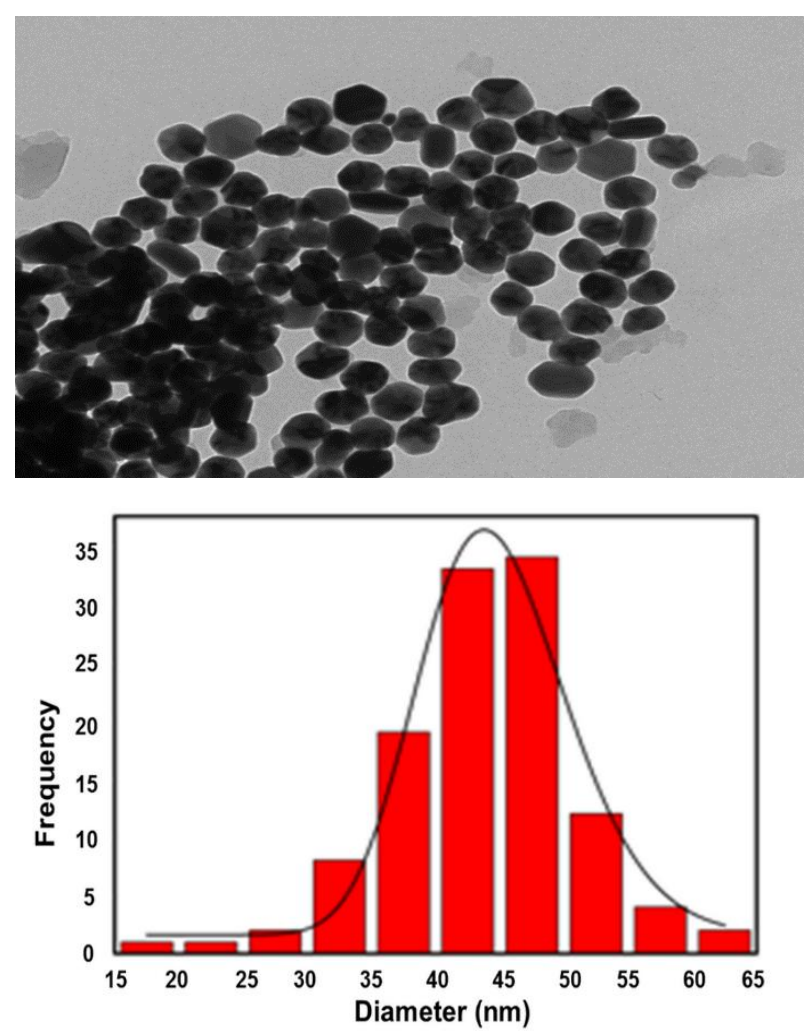

Figure 2. TEM images of the silver nanoparticles synthesized. 


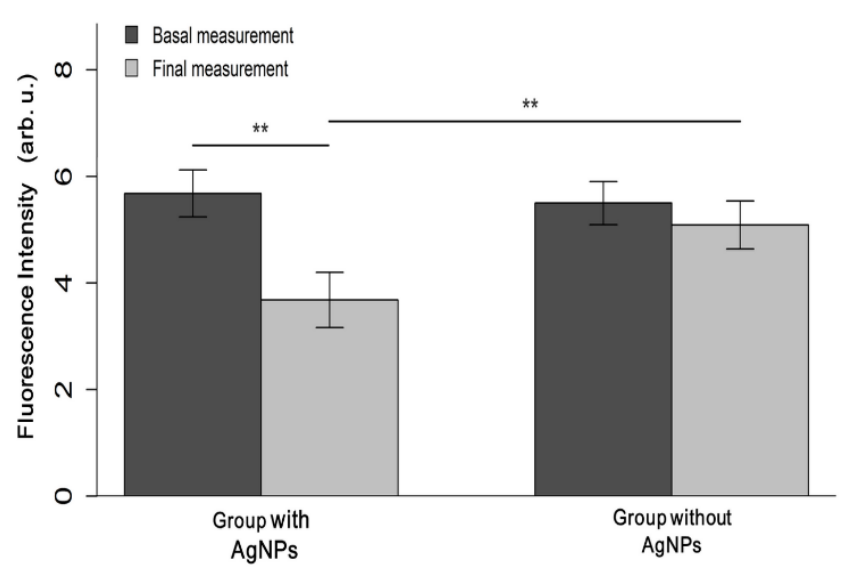

Figure 3. Changes in dental structure, arbitrary units from basal and final measurements are presented for both treatment groups. It was found significant differences between final measurements, and between basal and final measurements in the experimental group. Asterisks indicate p-values under 0.001 .

which signifies an increase of dental remineralization in this group. In the experimental treatment group, it was found less fluorescence intensity after 3 months of treatment $(3.68 \pm 1.2)$, as compared to the basal measurement $(5.68 \pm 1.0, \mathrm{p}<0.001)$. We did not find significant differences in the measurements of the control group $(\mathrm{p}=0.051)$ (Figure 3$)$.

New materials are continually being introduced into dental practice. These materials require examination to confirm the properties they claim to possess. The application of fluoride agents in different forms has been the most effective and frequently employed method used in the prevention dental caries [1].

These results suggest that the addition of AgNPs to a fluoride varnish seems to promote the dental remineralization. These findings indicate that this treatment strategy could not only prevent the progression of white spot lesions, but that it may revert the process, as evidenced by the reduction in the DIAGNOdent ${ }^{\circledR}$ fluorescence intensity after 3 months of treatment.

Fluoride ions in varnishes have been shown to promote the dental remineralization, either alone or in combination with other compounds [17]. Many studies have shown that fluoride varnishes can reverse or arrest the demineralization process of WSLs when combined with other preventive measures, such as diet control and reduction of dental biofilm [3]. Several studies have indicated fluoride varnishes to be clinically effective [2] due to their high concentration and safety during application [17]. In several studies, the AgNPs have been applied to dental materials, which have shown that can change mechanical properties of dental materials. AgNPs used in dental materials have good antimicrobial properties due to their efficacy in small doses, minimal toxicity, and minimal side effects [18]. Therefore we suppose that these particles may act synergistically to improve the dental remineralization, although studies to assess this claim must be performed, our hypothesis is based that since AgNPs exhibit microbial properties; there is a reduction in the number of bacteria adhering to the varnish, thus allowing an increase of dental remineralization.
We believe that our results have children impact; it's primordial to educate them and their parents about the risk of developing oral health related issues, and in the need of prophylactic measures to avoid this issues. The application of a fluoride varnish added with AgNPs seems to be a measure that can be used safely, and it has been shown to possess effectiveness for at least three months. The observation of an increase in the dental structure treated with fluoride varnish with AgNPs is a promising finding for its use as a prophylactic agent for caries prevention.

\section{Conclusions}

The effectiveness of repeated applications of a fluoride varnish that contains $0.1 \% 46 \mathrm{~nm} \mathrm{AgNPs}$ in the treatment of white spot lesions in children was demonstrated. We found results of dental remineralization after 3 months of application; thus, this strategy the addition with AgNPs to the varnish is a promissory treatment for dental remineralization and strengthening enamel to protect against dental caries.

\section{Acknowledgements}

This study was partially supported by the Consejo Nacional de Ciencia y Tecnología (CONACYT) Grant CB2010-01-153675 and the scholarship \#274282.

\section{References}

[1]. N. Tuloglu, S. Bayrak, E.S. Tunc, F Ozer, BMC Oral Health 16, $103(2016)$.

[2]. S.G. Virupaxi , N.M. Roshan , P. Poornima, N.B. Nagaveni , I.E. Neena, K.P. Bharath, J. Clin. Diagn. Res. 10, ZC33 (2016).

[3]. M. Du, N. Cheng, B. Tai, H. Jiang, J. Li, Z. Bian, Clin. Oral Investig. 16, 463 (2012).

[4]. C. Stecksén-Blicks, G. Renfors, N.D. Oscarson, F. Bergstrand, S. Twetman, Caries Res. 41, 455 (2007).

[5]. J.M. Ferreira, A.K. Aragão, A.D. Rosa, F.C. Sampaio, V.A. Menezes, Braz. Oral Res. 23, 446 (2009).

[6]. P.C. Siqueira, A.P. Magalhães, W.C. Pires, F.C. Pereira, E.P. Silveira-Lacerda, M.S. Carrião, A.F. Bakuzis, C.A. Souza-Costa, L.G. Lopes, C. Estrela, J. Clin. Exp. Dent. 7, e622 (2015).

[7]. J.M. Corrêa, M. Mori, H.L. Sanches, A.D. da Cruz, E Jr Poiate, I.A. Poiate, Int. J. Biomater. 2015, 485275 (2015).

[8]. H.H. Lara, E.N. Garza-Treviño, L. Ixtepan-Turrent, D.K. Singh, J. Nanobiotechnol. 9, 30 (2011).

[9]. R. García-Contreras, L. Argueta-Figueroa, C. MejíaRubalcava, R. Jiménez-Martínez, S. Cuevas-Guajardo, P.A. Sánchez-Reyna, H. Mendieta-Zerón, Int. Dent. J. 61, 297 (2011).

[10]. J.F. Hernández-Sierra, E.K. Salas-López, F. MartínezGutiérrez, F. Ruíz, M. Pierdant-Pérez, P. Mandeville, A.J. PozosGuillén, J. Clin. Pediatr Dent. 35, 183 (2010).

[11]. J.F. Hernández-Sierra, F. Ruíz, J.P. Castañedo-Cázares, V. Martínez-Ruiz, P. Mandeville, M. Pierdant-Pérez, A. GordilloMoscoso, A. Pozos-Guillén, J. Clin. Pediatr. Dent. 35, 65 (2010).

[12]. J.F. Hernández-Sierra, O. Galicia-Cruz, S.A. Angélica, F. Ruíz, M. Pierdant-Pérez, A.J. Pozos-Guillén, J. Clin. Pediatr. Dent. 36, 37 (2011).

[13]. M.E. Samberg, S.J. Oldenburg, N.A. Monteiro-Riviere, Environ. Health Perspect. 118, 407 (2010).

[14]. S. Eckhardt, P.S. Brunetto, J. Gagnon, M. Priebe, B. Giese, K.M. Fromm, Chem. Rev. 113, 4708 (2013).

[15]. J.E. Morales-Sánchez, J. Guajardo-Pacheco, M. Noriega- 
Treviño, C. Quintero-González, M. Compeán-Jasso, F. LópezSalinas, J. González-Hernández, F. Ruiz, Mater. Sci. Appl. 2, 578 (2011).

[16]. J.F. Hernández-Sierra, F. Ruiz, D.C. Pena, F. MartínezGutiérrez, A.E. Martínez, Ade J. Guillén, H. Tapia-Pérez, G.M. Castañón, Nanomed. 4, 237(2008).
[17]. M.Q. Almeida, O.X. Costa, J.M. Ferreira, V.A. Menezes, R.B. Leal, F.C. Sampaio, Braz. Dent. J. 22, 193 (2011).

[18]. R. Haghgoo, H. Saderi, M. Eskandari, H. Haghshenas, M. Rezvani, J. Dent. (Shiraz) 15, 57 (2014).

(C) 2017 by the authors; licensee SMCTSM, Mexico. This article is an open access article distributed under the terms and conditions of the Creative Commons Attribution license (http://creativecommons.org/licenses/by/4.0/). 